\title{
ANALYSIS OF THE SPECIFIC EFFORT IN PERFORMANCE JUDO
}

\author{
Laurențiu BOCIOAC $\breve{1}^{1 *}$ \\ ${ }^{1}$ National University of Physical Education and Sport, Faculty of Physical Education and Sport, Bucharest, Romania \\ *Corresponding author: laurbocioaca@yahoo.com
}

DOI: 10.35189/iphm.icpesk.2019.6

\begin{abstract}
Judo, an Olympic sport, includes techniques performed with maximum efficiency and minimum effort. Specialists consider that the biomechanics of combat actions and the specificity of physical training and exercise capacity are increasingly important. The purpose of this paper is to highlight the characteristics of exercise capacity specific to the training and competitive activities for senior performance judo athletes. The characteristics of aerobic and anaerobic effort are determined in this study, as well as the relationship between them and the training methods that should be developed for performance judo athletes. The research subjects are male and female performance and high-performance athletes aged 19 to 21 years, participants in national and international competitions. The research used general and specific methods aimed at assessing and enhancing aerobic and anaerobic exercise capacity. For the assessment of specific anaerobic capacity, methods for measuring the level of blood lactic acid and laboratory spectrophotometry are used. Aerobic capacity is assessed by spirometry and digitised pulse oximetry methods. Data on exercise capacity were collected during training and the execution of combat actions specific to the competitive activity. Data on maximum oxygen uptake and calorie consumption specific to judo effort are also presented using the comparative calorimetric and thermographic system assessment. The research findings demonstrate the importance of assessing aerobic and anaerobic exercise capacity in the training of performance judo athletes in order to achieve the intended adaptive effects for increasing efficiency in the execution of combat actions during top-level competitions.
\end{abstract}

Keywords: judo, effort, performance, training.

\section{Introduction}

The increasing performance capacity of judo athletes is the result of the continuous increase in exercise capacity and the improvement of assessment methods. Performance judo athletes are adapted to high-intensity effort. Permanent optimisation of maximum anaerobic capacity and aerobic capacity by using specific training and assessment means and methods is a constant desideratum of research in performance judo.

Numerous studies demonstrate the importance of determining anaerobic alactic and lactic exercise capacity and aerobic exercise capacity in performance judo athletes (Franchini, Artioli, \& Brito, 2013).

The methods for determining exercise capacity in laboratory and training conditions allow selecting the training means in conditions as close possible to judo-specific demands (Artioli et al., 2012).

Specific demands in performance judo require the assessment of exercise capacity in accordance with the biomechanics of technical executions (Sale, McDougall, Jacobs, \& Garner, 1990).

The fundamental changes in the structure of demands specific to top-level judo competitions require adaptations to the anaerobic lactic effort (Hantău \& Bocioacă, 1998).

The purpose of our research is to determine the exercise capacity of judo athletes based on the demands specific to this sports discipline.

\section{Material and Methods}

Our paper presents data collected throughout a training macrocycle from 20 male and female senior athletes of international and national standing, aged 19 to 21 years, in different weight classes, members of the judo teams within the Romanian Judo Federation. Data on exercise capacity were collected during training and the execution of combat actions (Petre, Murărețu, \& Teodoru, 2014) specific to the competitive activity (Imamura, Iteya, Hreljac, \& Escamilla, 2007). Data on aerobic and anaerobic exercise capacity indicators, as well as exercise capacity indicators, were provided to us by the Romanian Judo Federation.

For the assessment of specific anaerobic capacity, methods to determine the level of blood lactic acid and laboratory spectrophotometry are used. Aerobic capacity is assessed by spirometry and digitised pulse oximetry methods.

To determine exercise capacity, two assessments were performed: initially, at the beginning of the training macrocycle, and finally, on completion of the macrocycle. To determine anaerobic capacity, the Sargent test was 
used initially and finally. The amount of blood lactic acid (LA mmol/L) was measured at the end of two 5-minute rounds and after a 5-minute break in order to reach the demand specific to the intensity of the fight (Nicu, 1993).

For the assessment of aerobic capacity, the digitised spirometry test was applied to determine forced vital capacity (FVC) and forced maximum expiratory flow, and the digitised pulse oximetry $\left(\mathrm{SpO}_{2}\right)$ method was used to measure blood oxyhaemoglobin saturation (Beneke, Pollmann, Bleif, Leithäuser, \& Hütler, 2002).

The results of the two $\mathrm{FVC} / \mathrm{SpO}_{2}$ tests are shown in Table 3, with average values for both indicators. As regards the tests applied to the research subjects, the collected data were statistically processed by calculating the arithmetic mean, standard deviation (STDEVP) and variation (VARP), Student's t-distribution (t-Test).

The data are shown in Tables 1-3 and graphically represented in Figures 1-7.

\section{Results}

Table 1. Initial and final test data for aerobic $\left(\mathrm{VO}_{2}\right)$ and anaerobic exercise capacity - Sargent test $(W)$

\begin{tabular}{|c|c|c|c|c|c|c|}
\hline $\begin{array}{l}\text { Name } \\
\text { initials }\end{array}$ & $\begin{array}{c}\text { Female/ } \\
\text { Male }\end{array}$ & $\begin{array}{l}\text { Weight class } \\
\qquad(\mathrm{kg})\end{array}$ & $\begin{array}{c}\text { Initial } \\
\text { test } \mathrm{VO}_{2}\end{array}$ & $\begin{array}{c}\text { Final } \\
\text { test } \mathrm{VO}_{2}\end{array}$ & $\begin{array}{c}\text { Initial Sargent } \\
\text { test }(\mathrm{W})\end{array}$ & $\begin{array}{c}\text { Final Sargent } \\
\text { test }(\mathrm{W})\end{array}$ \\
\hline C.I. & $\mathrm{F}$ & 48 & 31 & 33 & 144.18 & 150.5 \\
\hline V.C. & F & 57 & 28 & 30 & 123.47 & 130.11 \\
\hline I.N. & $\mathrm{F}$ & 78 & 43 & 46 & 150.32 & 157 \\
\hline D.A. & $\mathrm{F}$ & 52 & 38 & 40 & 140.97 & 130.96 \\
\hline C.C. & $\mathrm{F}$ & 48 & 36 & 38 & 129.73 & 179.36 \\
\hline R.S. & M & 95 & 40 & 42 & 162.58 & 156.05 \\
\hline C.A. & $\mathrm{F}$ & 48 & 32 & 35 & 150.32 & 148.24 \\
\hline C.M. & $\mathrm{F}$ & 48 & 30 & 36 & 158.88 & 167.89 \\
\hline L.A. & M & 66 & 33 & 37 & 115.6 & 123.35 \\
\hline M.A. & $\mathrm{F}$ & 52 & 28 & 30 & 166.34 & 171.61 \\
\hline P.A. & M & 73 & 32 & 34 & 146.67 & 154.36 \\
\hline S.N. & $\mathrm{F}$ & 52 & 33 & 36 & 143.15 & 153.37 \\
\hline B.C. & M & 81 & 35 & 38 & 144.7 & 165.76 \\
\hline G.V. & M & 66 & 30 & 34 & 150.32 & 162.15 \\
\hline C.E. & $\mathrm{F}$ & 57 & 33 & 35 & 142.67 & 150.21 \\
\hline S.C. & F & 52 & 31 & 33 & 117.46 & 167.42 \\
\hline B.R. & $\mathrm{F}$ & 52 & 35 & 37 & 115.3 & 126.35 \\
\hline D.S. & M & 73 & 37 & 40 & 143.72 & 135.69 \\
\hline F.L. & M & 100 & 43 & 45 & 136.73 & 157.81 \\
\hline \multirow[t]{5}{*}{ A.D. } & M & 100 & 41 & 44 & 140.54 & 160.15 \\
\hline & & AVERAGE & 34.45 & 37.15 & 141.18 & 152.41 \\
\hline & & STDEVP & 4.51 & 4.45 & 14.27 & 15.41 \\
\hline & & VARP & 20.3 & 19.8 & 203.5 & 237.4 \\
\hline & & t-Test & 1.95 & & 0.02 & \\
\hline
\end{tabular}

Table 2. Initial and final test data for aerobic lactic capacity LA (mmol/L)

\begin{tabular}{lcccc}
\hline $\begin{array}{c}\text { Name } \\
\text { initials }\end{array}$ & $\begin{array}{c}\text { Female/ } \\
\text { Male }\end{array}$ & $\begin{array}{c}\text { Weight class } \\
(\mathrm{kg})\end{array}$ & $\begin{array}{c}\text { Initial LA } \\
(\mathrm{mmol} / \mathrm{L})\end{array}$ & $\begin{array}{c}\text { Final LA } \\
(\mathrm{mmol} / \mathrm{L})\end{array}$ \\
\hline C.I. & $\mathrm{F}$ & 48 & 11.51 & 21.51 \\
V.C. & $\mathrm{F}$ & 57 & 12.54 & 22.53 \\
I.N. & $\mathrm{F}$ & 78 & 12.18 & 23.42 \\
D.A. & $\mathrm{F}$ & 52 & 10.32 & 21.15 \\
C.C. & $\mathrm{F}$ & 48 & 13.45 & 16.18 \\
R.S. & $\mathrm{M}$ & 95 & 14.15 & 19.32 \\
C.A. & $\mathrm{F}$ & 48 & 12.26 & 20.18 \\
C.M. & $\mathrm{F}$ & 48 & 14.64 & 21.16
\end{tabular}


International Proceedings of Human Motricity/ ICPESK 2019 Supplementary Issue of Discobolul - Physical Education, Sport and Kinetotherapy Journal, 2019

\begin{tabular}{lcccc} 
L.A. & $\mathrm{M}$ & 66 & 10.27 & 15.43 \\
M.A. & $\mathrm{F}$ & 52 & 11.52 & 16.45 \\
P.A. & $\mathrm{M}$ & 73 & 14.51 & 20.5 \\
S.N. & $\mathrm{F}$ & 52 & 13.45 & 18.71 \\
B.C. & $\mathrm{M}$ & 81 & 12.23 & 21.78 \\
G.V. & $\mathrm{M}$ & 66 & 11.57 & 19.81 \\
C.E. & $\mathrm{F}$ & 57 & 14.52 & 21.23 \\
S.C. & $\mathrm{F}$ & 52 & 16.32 & 19.43 \\
B.R. & $\mathrm{F}$ & 52 & 16.46 & 22.18 \\
D.S. & $\mathrm{M}$ & $\mathrm{T}$ & 19.43 & 23.14 \\
F.L. & $\mathrm{M}$ & 100 & 16.68 & 19.12 \\
A.D. & $\mathrm{M}$ & 100 & 15.36 & 20.42 \\
& & AVERAGE & 13.66 & 20.18 \\
& & STDVP & 2.30 & 2.16 \\
& & VARP & 5.33 & 4.67 \\
\hline
\end{tabular}

Table 3. Initial and final test data for aerobic capacity - Spirometry $(\mathrm{FVC})$ and digitised pulse oximetry $\left(\mathrm{SpO} \mathrm{O}_{2}\right)$ tests

\begin{tabular}{lcccc}
\hline $\begin{array}{c}\text { Name } \\
\text { initials }\end{array}$ & $\begin{array}{c}\text { Female/ } \\
\text { Male }\end{array}$ & $\begin{array}{c}\text { Weight class } \\
(\mathrm{kg})\end{array}$ & $\begin{array}{c}\text { Initial Spirometry test } \\
\left(\mathrm{FVC} / \mathrm{SpO}_{2}\right)\end{array}$ & $\begin{array}{c}\text { Final Spirometry test } \\
\left(\mathrm{FVC} / \mathrm{SpO}_{2}\right)\end{array}$ \\
\hline C.I. & $\mathrm{F}$ & 48 & 90 & 97 \\
V.C. & $\mathrm{F}$ & 57 & 94 & 98 \\
I.N. & $\mathrm{F}$ & 78 & 99 & 99 \\
D.A. & $\mathrm{F}$ & 52 & 90 & 94 \\
C.C. & $\mathrm{F}$ & 48 & 87 & 90 \\
R.S. & $\mathrm{M}$ & 95 & 92 & 94 \\
C.A. & $\mathrm{F}$ & 48 & 94 & 94 \\
C.M. & $\mathrm{F}$ & 48 & 97 & 100 \\
L.A. & $\mathrm{M}$ & 66 & 99 & 100 \\
M.A. & $\mathrm{F}$ & 52 & 96 & 99 \\
P.A. & $\mathrm{M}$ & 73 & 90 & 97 \\
S.N. & $\mathrm{F}$ & 52 & 97 & 100 \\
B.C. & $\mathrm{M}$ & 81 & 98 & 100 \\
G.V. & $\mathrm{M}$ & 66 & 97 & 97 \\
C.E. & $\mathrm{F}$ & 57 & 98 & 98 \\
S.C. & $\mathrm{F}$ & 52 & 94 & 96 \\
B.R. & $\mathrm{F}$ & 52 & 97 & 97 \\
D.S. & $\mathrm{M}$ & 71 & 93 & 100 \\
F.L. & $\mathrm{M}$ & 100 & 96 & 97 \\
A.D. & $\mathrm{M}$ & 100 & 99 & 98 \\
& & AVERAGE & 94.85 & 97.25 \\
& & STDVP & 3.45 & 6.56 \\
& & VARP & 11.92 & \\
\hline
\end{tabular}




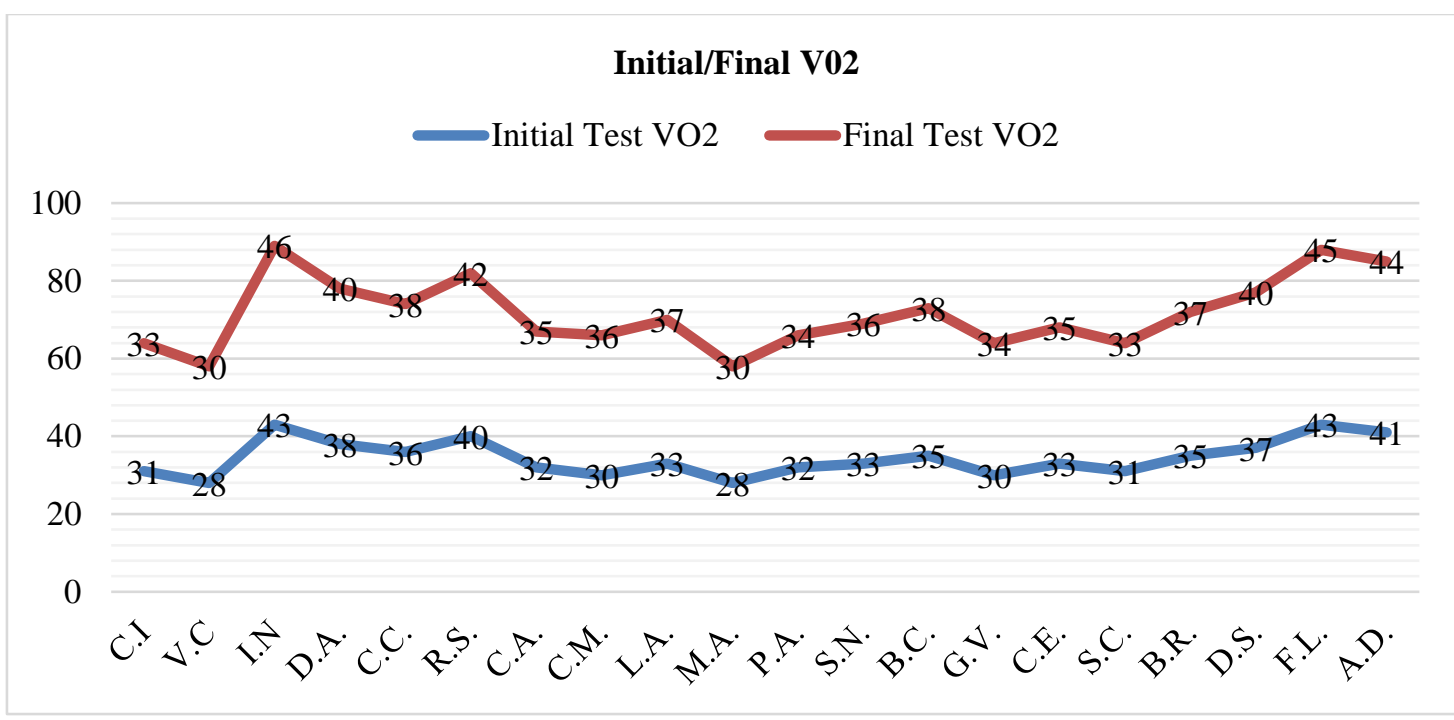

Figure 1. Evolution of aerobic capacity - Maximum oxygen uptake $\left(\mathrm{VO}_{2}\right)$ in initial and final testing

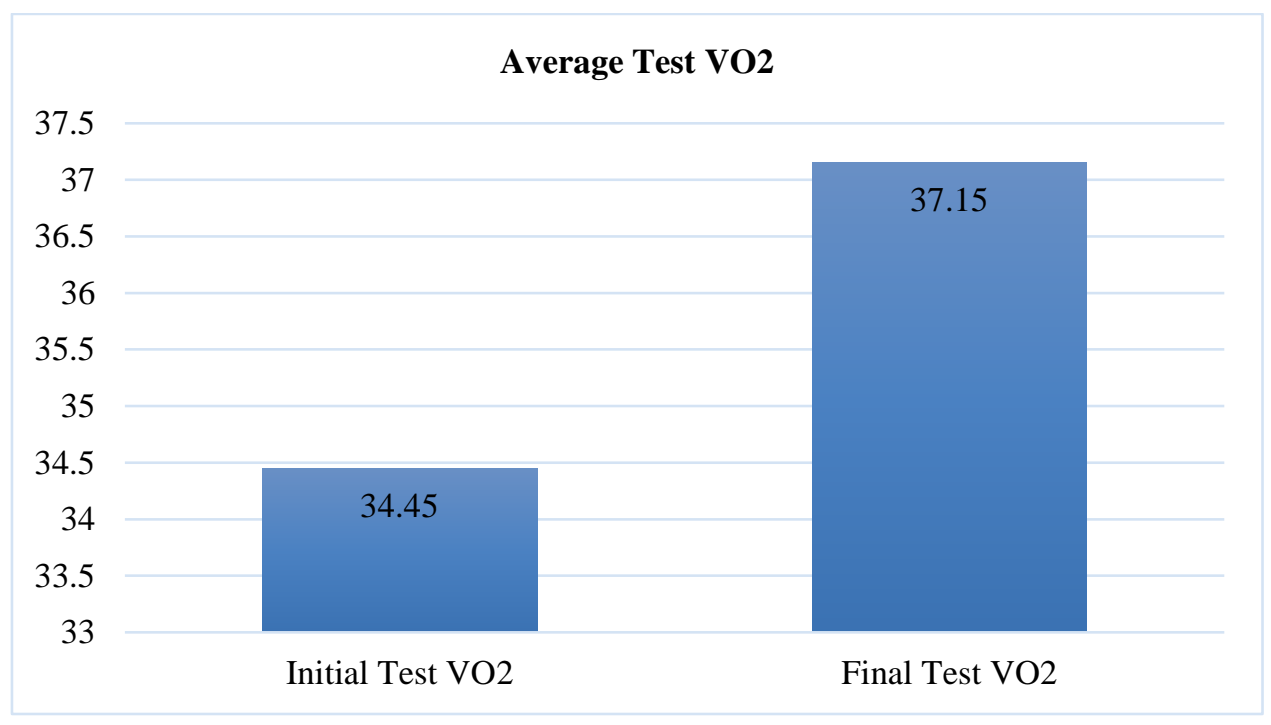

Figure 2. Evolution of average $\mathrm{VO}_{2}$ values in initial and final testing

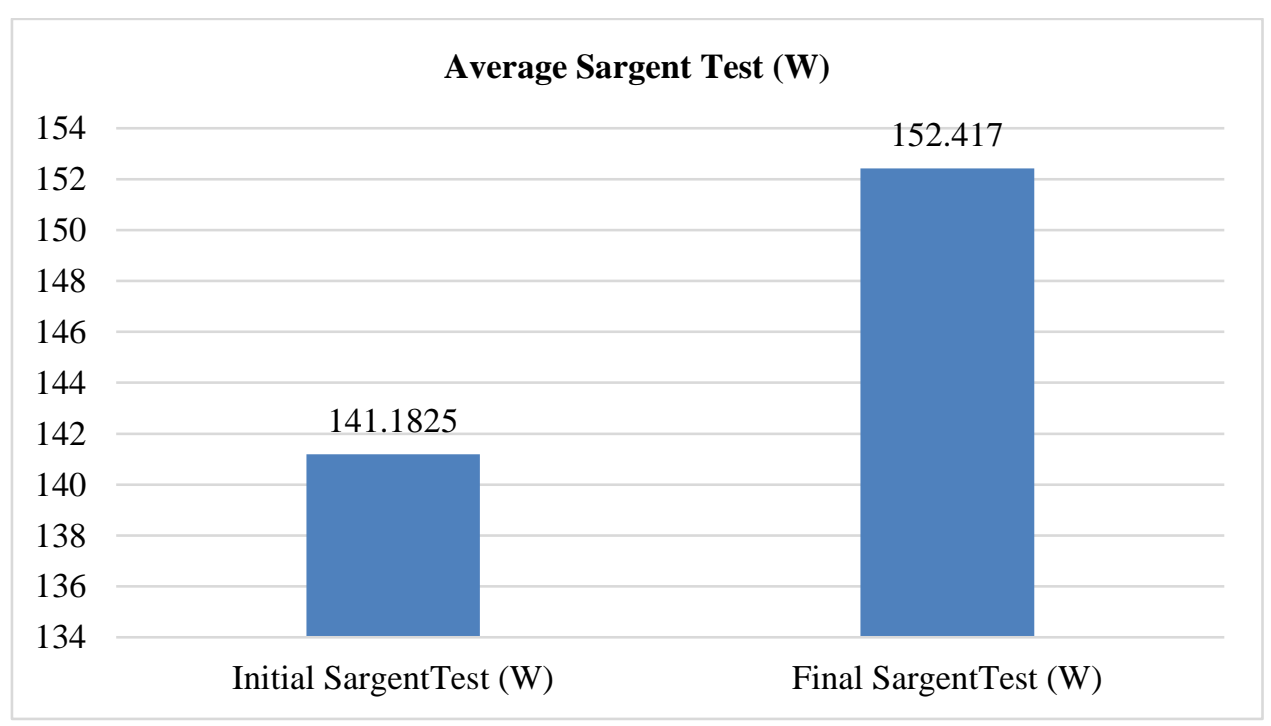

Figure 3. Evolution of average values for the Sargent test in initial and final testing 


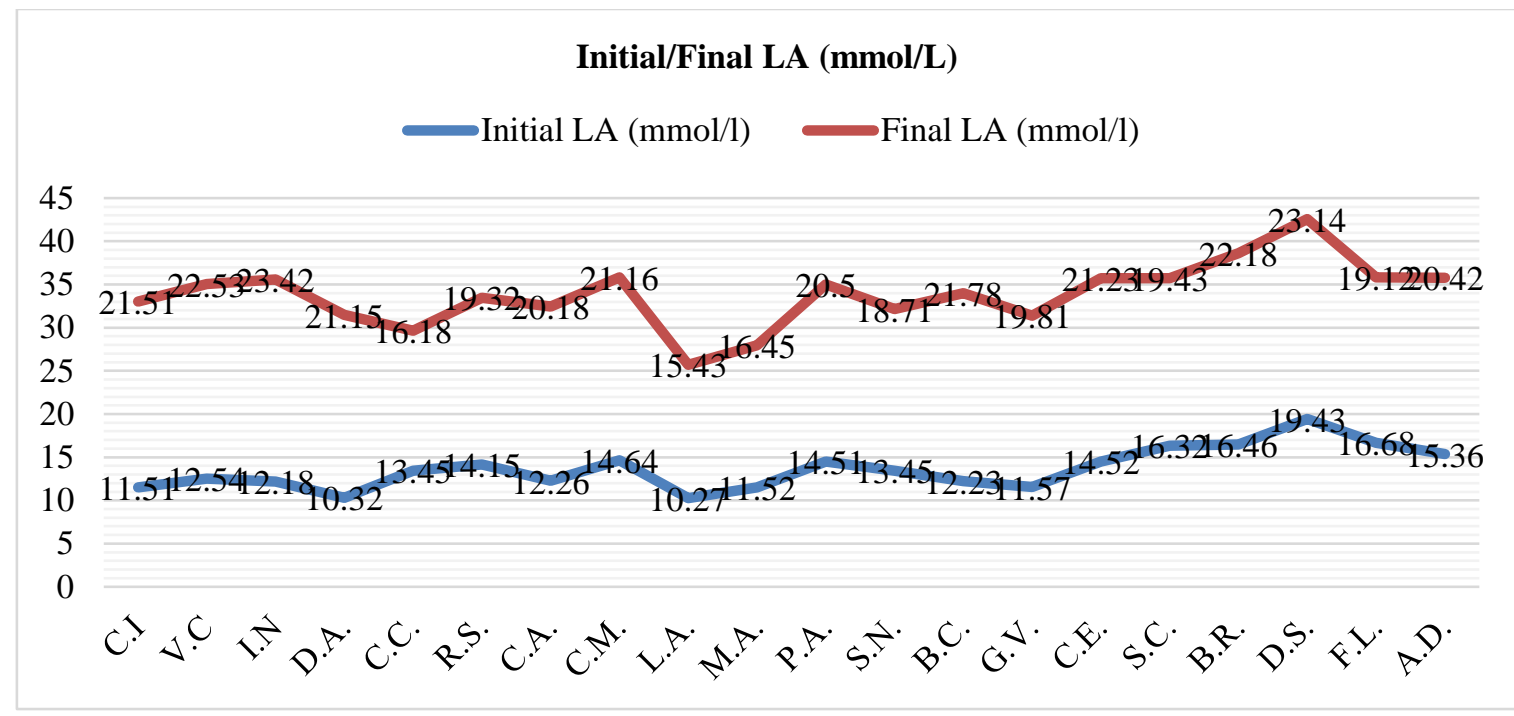

Figure 4. Evolution of anaerobic capacity - The amount of blood lactic acid LA (mmol/L) in initial and final testing

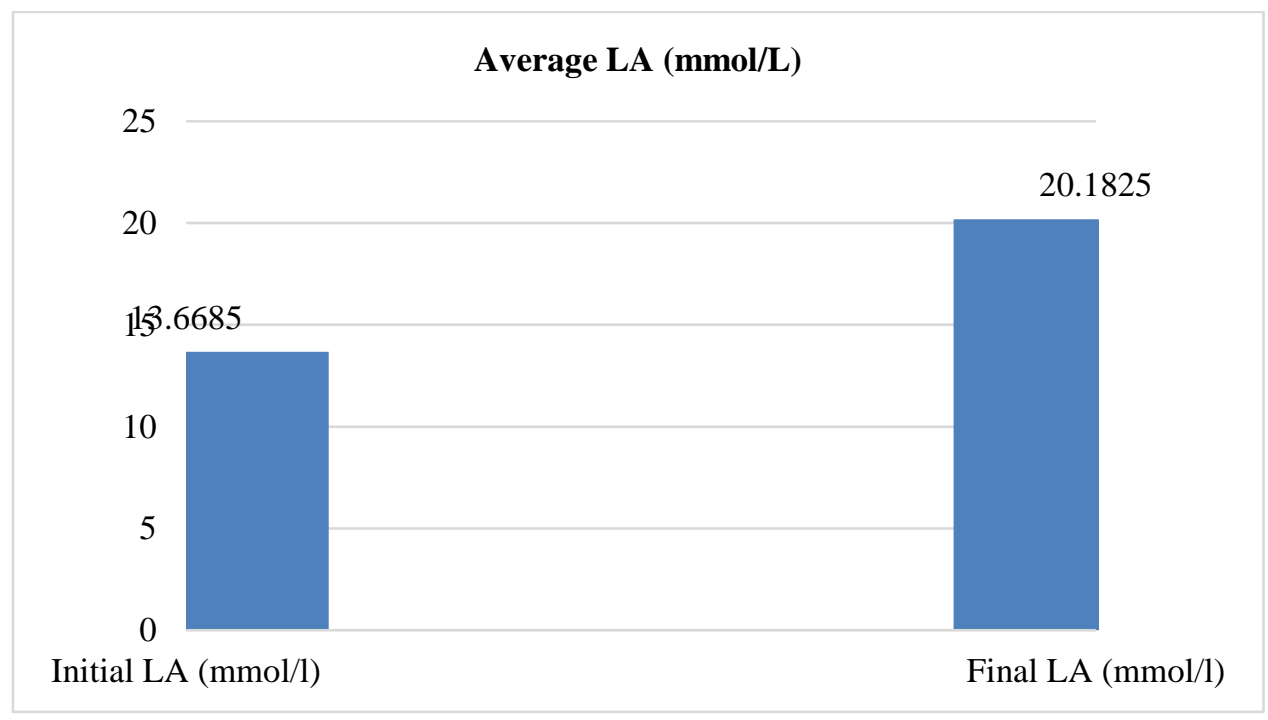

Figure 5. Evolution of average values - The amount of blood lactic acid LA (mmol/L) in initial and final testing

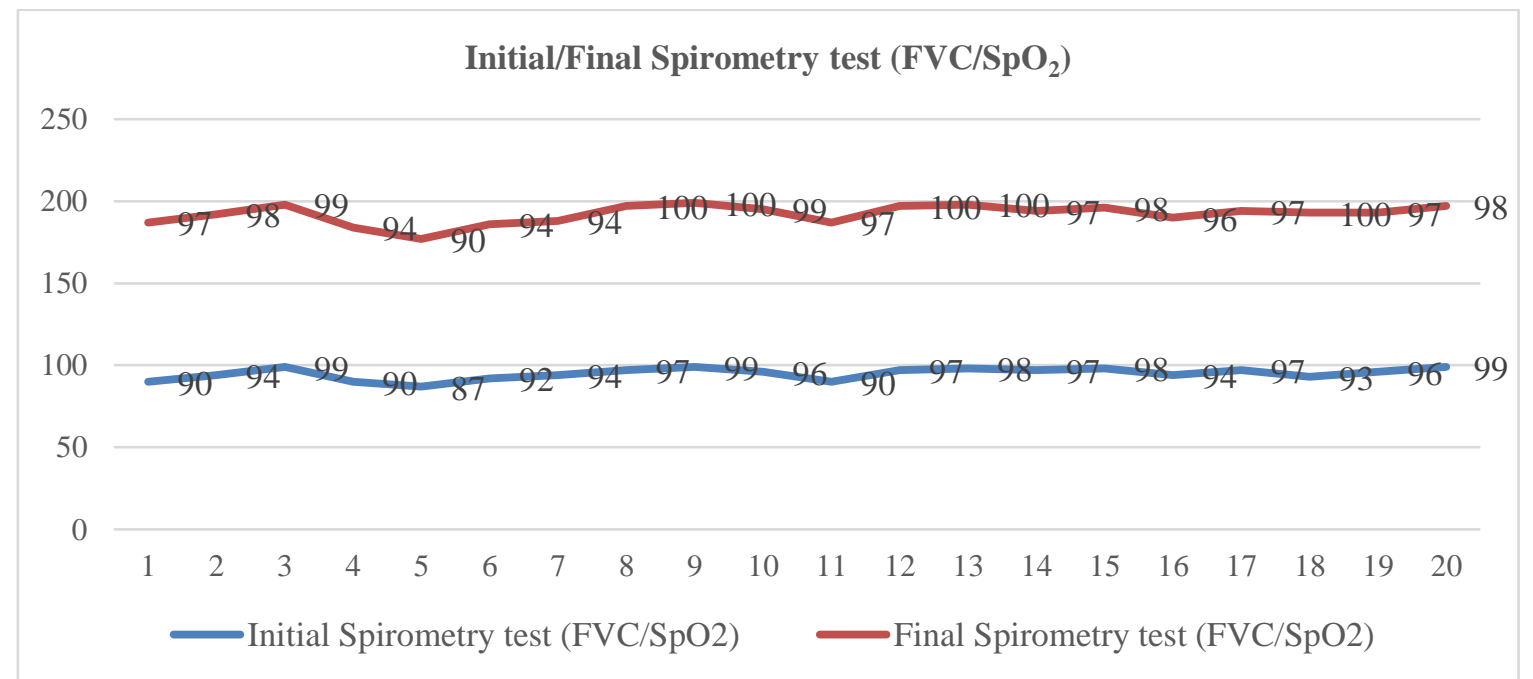

Figure 6. Evolution of aerobic capacity - The amount of blood lactic acid LA (mmol/l) in initial and final testing 


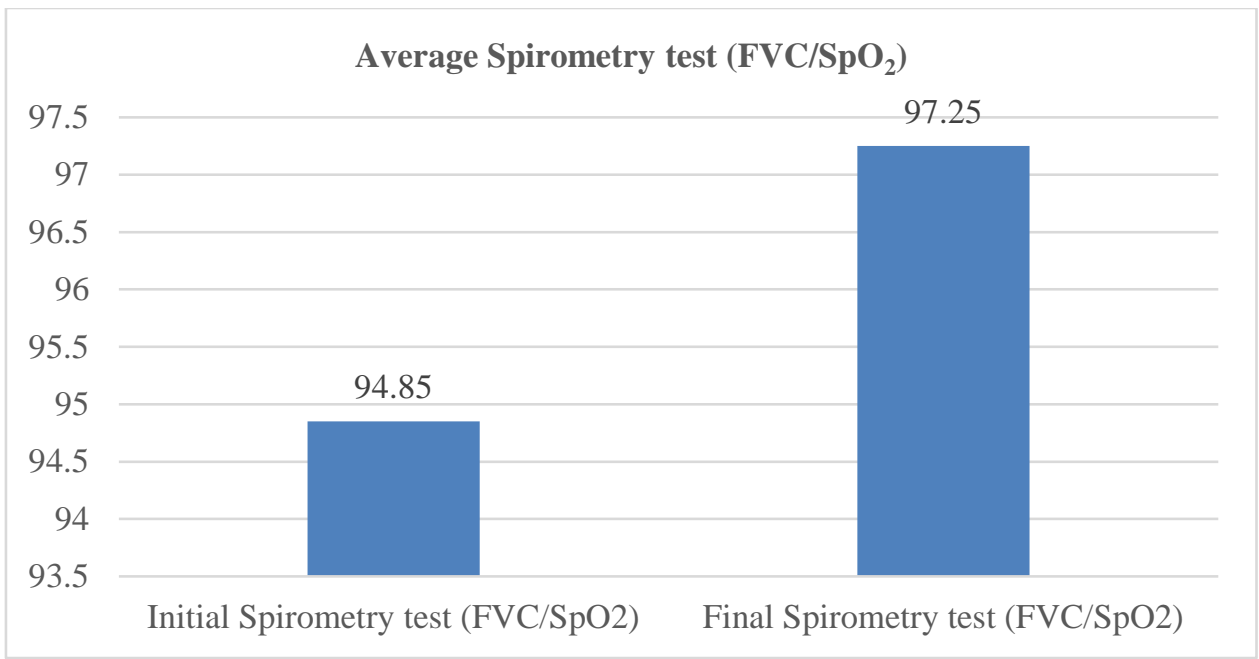

Figure 7. Evolution of average values - Spirometry $(\mathrm{FVC})$ and digitised pulse oximetry $\left(\mathrm{SpO}_{2}\right)$ tests

\section{Conclusion}

The data presented in this research highlight a significant increase in exercise capacity throughout the training macrocycle of senior performance judo athletes, according to initial and final assessments.

Aerobic capacity, by the recorded values for maximum oxygen uptake $\left(\mathrm{VO}_{2}\right)$, has an average level of development. The results from spirometry (FVC) and digitised pulse oximetry $\left(\mathrm{SpO}_{2}\right)$ tests show normal vital capacity, with an insignificant increase in the final test results (t-Test). The amount of blood lactic acid, by the average values recorded in the two LA (mmol/l) tests, is significantly increased after three combat rounds, both in initial and final testing, due to maximal intensity of the effort specific to judo combat and training.

The research data emphasise an increased adaptation of anaerobic lactic and alactic exercise capacity, with an average level of adaptation to aerobic effort. This predominant trend, revealed by the data obtained after assessing the performance capacity characteristics, shows a significant increase in anaerobic lactic exercise capacity and average values of aerobic capacity, which indicates major changes in the training concept of judo athletes and specialists in order to avoid wasting energy and time through efficient training adapted to competitive demands.

\section{References}

Artioli, G. G., Bertuzzi, R. C., Roschel, H., Mendes, S. H., Lancha Jr., A. H., \& Franchini, E. (2012). Determining the contribution of the energy systems during exercise. Journal of Visualized Experiments, 61: 3413. https://doi.org/10.3791/3413

Beneke, R., Pollmann, C., Bleif, I., Leithäuser, R. M., \& Hütler, M. (2002). How anaerobic is the Wingate Anaerobic Test for humans. European Journal of Applied Physiology, 87(4-5), 388-392. https://doi.org/10.1007/s00421-002-0622-4

Franchini, E., Artioli, G. G., Brito, C. J. (2013). Judo combat: Time-motion analysis and physiology. International Journal of Performance Analysis in Sport, $13(3), \quad 624-641$. https://doi.org/10.1080/24748668.2013.11868676

Hantău, I., \& Bocioacă, L. (1998). Antrenamentul în judo: Pregătirea fizică şi tehnică [Judo training: Physical and technical preparation]. Piteşti: Editura Universității din Pitești.

Imamura, R., Iteya, M., Hreljac, A., \& Escamilla R. (2007). A kinematic comparison of the judo throw HaraiGoshi during competitive and non-competitive conditions. Journal of Sports Science and Medicine, 6(CSSI-2), 15-22. Retrieved from https://www.ncbi.nlm.nih.gov/pmc/articles/PMC3809049/

Nicu, A. (Red.) (1993). Antrenamentul sportiv modern [Modern sports training]. Bucureşti: Editis.

Petre, R. L., Murărețu, D. C., \& Teodoru, M. (2015). Implementation of a program based on specific means for the execution speed development in karate-do. In M. Stănescu \& M. Păunescu (Ed.), 4th International Congress of Physical Education, Sport and Kinetotherapy (ICPESK 2014, pp. 187-102). Bologna: Medimond. Retrieved from http://www.unefs.ro/internationalcongress/archive/2014/Performance_Sport_2014.pdf

Sale, D. G., McDougall, J. D., Jacobs, I., \& Garner, S. (1990). Interaction between concurrent strength and endurance training. Journal of Applied Physiology, 68(1), 260-270. https://doi.org/10.1152/jappl.1990.68.1.260 